\title{
1 Quantification of chrysolaminarin from the model diatom Phaeodactylum
}

\section{2 tricornutum}

3

4 Michael A. Caballero ${ }^{1,2}$, Denis Jallet ${ }^{1}$, Libin $\mathrm{Shi}^{3}$, Chris Rithner $^{4}$, Yun Zhang ${ }^{1}$ and Graham 5 Peers $^{1,2}$

$7 \quad{ }^{1}$ Department of Biology, ${ }^{2}$ Cell and Molecular Biology Program, ${ }^{3}$ Department of Microbiology,

8 Immunology \& Pathology, \& ${ }^{4}$ Central Instrument Facility, Colorado State University, Fort

9 Collins, CO 80523

\section{Abstract}

12 We have established a protocol that allows for parallel quantification of three carbohydrate pools

13 in the marine diatom Phaeodactylum tricornutum. This method utilizes a series of extraction and

14 digestion steps followed by the employment of the 3-methyl-2-benzothiazolinone hydrazone

15 (MBTH) reducing sugar assay. Comparing carbohydrate content between hydrolyzed and non-

16 hydrolyzed soluble extracts enables quantification of soluble, nonreducing carbohydrate. The

17 latter fraction contains chrysolaminarin as verified by ${ }^{1} \mathrm{H}-\mathrm{NMR}$ and monomer composition of the

18 purified glucan. We applied this method to investigate carbon partitioning in two experiments.

19 We observed the accumulation of chrysolaminarin during the day and near complete

20 consumption in the dark, supporting its role for fueling heterotrophic metabolism at night. We

21 then observed little change in chrysolaminarin accumulation or consumption during nitrogen

22 starvation, a condition that is known to increase the cellular content of the biofuel precursor

23 triacylglycerol. Overall, this method improves the resolution of major carbohydrate pools in 
24 diatoms, complementing physiological and systems biology studies interested in exploring

25 diatom metabolism.

\section{Keywords}

28 Diatoms, Phaeodactylum tricornutum, carbohydrate, chrysolaminarin, nitrogen starvation, 29 carbon partitioning

31 1. Introduction

32 Diatoms are important contributors to the biogeochemical cycling of carbon, contributing

33 as much as one-fifth of annual net primary productivity [1]. Diatoms allocate organic carbon into

34 two primary storage metabolites: the neutral lipid triacylglycerol (TAG) and the storage

35 polysaccharide chrysolaminarin [2,3]. TAG is a major carbon reserve, especially during nutrient

36 stress [4]. TAG productivity is of interest for biofuel production, as these neutral lipids are an

37 important precursor for the production of biodiesel [5]. Diatoms have been identified as a

38 promising platform for biodiesel production because of their relatively high biomass and lipid

39 productivities relative to other algal species [6]. Simultaneously, diatoms synthesize

40 chrysolaminarin as a reserve carbohydrate. Chrysolaminarin has been characterized as soluble

41 polymer consisting of glucose monomers linked by a $\beta-1,3$ bond with limited $\beta-1,6$ branching

42 [7]. The average molecular weight and number of branches of chrysolaminarin can vary

43 significantly between species [8]. The structure and composition of chrysolaminarin is known;

44 however, the enzymes responsible for its creation and consumption remain broadly

45 uncharacterized [8]. Furthermore, the lack of an established quantification method limits our

46 understanding of this reserve polysaccharide as a fraction of total cellular carbon. 
Several studies have addressed the challenge of chrysolaminarin quantification by using a

48 warm-water extraction that quantifies insoluble carbohydrates and soluble carbohydrates in

49 parallel $[9,10]$. The diversity of insoluble and soluble carbohydrates produced by diatoms has

50 recently been reviewed [11]. Briefly, insoluble carbohydrates contain structural carbohydrates

51 associated with the frustule such as mannans [12], callose [13], and, in some species, chitin [14].

52 Soluble carbohydrates contain chrysolaminarin [7], exopolysaccharides [15], and free sugars in

53 metabolism. These insoluble and soluble fractions are typically quantified with total

54 carbohydrate assays such as phenol-sulfuric acid or anthrone methods [16, 17]. These

55 quantification methods do not differentiate between monosaccharides and polysaccharides.

56 Several recent studies have opted to observe diatom carbohydrate biochemistry by measuring

57 total carbohydrates with these assays [18-20]. However, quantifying soluble monosaccharides,

58 soluble polysaccharides (chrysolaminarin), and insoluble polysaccharides in parallel with a

59 reducing sugar assay [21] will provide more insight into carbon partitioning following genetic

60 manipulation or physiological conditions.

61 Metabolic engineering strategies in many photoautotrophs seek to increase the flux of

62 carbon and energy towards molecules of interest [5, 22]. The proportions of carbon found in the

63 two major carbon reserves of algae, neutral lipids and storage polysaccharides, can be

64 manipulated through changing physiological status or by disruption of biosynthetic pathways.

65 Nitrogen starvation is one of the best-characterized examples of manipulating metabolism:

66 increased TAG accumulation has been observed in a broad range of organisms from diatoms [23-

6727 ] to green algae [27-30] when nitrogen is removed from the medium.

69 proportion of cellular organic carbon is allocated as carbon reserves (both TAG and storage 
70 polysaccharides). It was reasoned that disrupting polysaccharide metabolism might further

71 increase the accumulation of TAG, as the displaced storage carbon from polysaccharides had to

72 be partitioned somewhere in metabolism. For instance, mixotrophically grown starchless

73 Chlamydomonas mutants accumulated even more TAG than wild type during nitrogen starvation

74 [31, 32]. Therefore, it is rational to suggest that manipulating chrysolaminarin metabolism may

75 enhance TAG productivity in diatoms. Several groups have investigated this possibility in

76 diatoms with a reverse genetics approach by knocking down or knocking out putative enzymes in

77 chrysolaminarin biosynthesis [33, 34], or by blocking $\beta-1,3$ glucanase activity [35]. All of these

78 studies reported an increase in TAG content; however, they could only infer a reduction in

79 chrysolaminarin accumulation. Conclusions about carbon repartitioning from chrysolaminarin to

80 other carbon sinks have broadly been limited by the inability to specifically quantify

81 chrysolaminarin from other major carbohydrate pools.

82 Our primary objective with this study was to establish a method to quantify

83 chrysolaminarin and thereby improve the biochemical toolkit of diatoms to study central carbon

84 metabolism. The method described here is based off of the sensitive and accurate 3-methyl-2-

85 benzothiazolinone hydrazone (MBTH) assay $[21,36]$. The MBTH assay has already been

86 applied to a range of carbohydrate quantification applications including field samples [37],

87 glycolytic assays [38, 39], and total carbohydrate content of algae [40]. It provides considerably

88 greater accuracy and precision compared to the commonly used anthrone and phenol-sulfuric

89 acid carbohydrate assays [40]. This assay is coupled to a workflow that quantifies three major

90 carbohydrate pools from Phaeodactylum tricornutum, including a soluble, nonreducing fraction

91 that contains chyrsolaminarin. We then applied this workflow to quantify the changes in carbon

92 partitioning to storage metabolites during nitrate starvation on a light/dark cycle. Our data 
93 indicate that, during nitrate starvation, chrysolaminarin per cell decreases and that TAG

94 represents the dominant reserve carbon molecule.

95

96 2. Materials and Methods

97 2.1. Extraction and analytical chemistry of carbohydrates

98 2.1.1. Culturing conditions

99 Batch cultures of axenic Phaeodactylum tricornutum CCAP 1055/1 (hereafter,

100 Phaeodactylum) were grown in $1 \mathrm{~L}$ Roux flasks with $0.8 \mathrm{~L}$ of artificial seawater (Instant Ocean,

$10135 \%$ salinity). Nutrients were added per the stoichiometry described by Guillard [41], but at a

102 2.3-fold higher concentration to mitigate any nutrient limitation. Silicon was omitted from the

103 medium, as it is not required for Phaeodactylum growth. Light was provided in a 12:12 day/night

104 cycle, where daytime irradiance was set at $420 \pm 20 \mu \mathrm{mol}$ photons $\mathrm{m}^{-2} \mathrm{~s}^{-1}$ (LI-COR light meter,

105 LI-250A, $2 \pi$ sensor). Five replicate cultures were grown at $18{ }^{\circ} \mathrm{C}$ and were mixed by sparging

106 with $1 \mathrm{~L} \mathrm{~min}^{-1}$ air. Cultures were maintained in exponential growth for at least two days prior to

107 the start of the experiment with serial dilutions.

108 2.1.2. Extraction and purification of soluble carbohydrate

109 The $4 \mathrm{~L}$ volume was harvested at dusk during exponential growth and cells were pelleted

110 by centrifugation $\left(3220 \times \mathrm{g}, 10 \mathrm{~min}, 18^{\circ} \mathrm{C}\right)$ in $50 \mathrm{~mL}$ conical tubes. All harvested cells were

111 combined into a single pellet, resuspended with $10 \mathrm{~mL}$ deionized water, and incubated at $50{ }^{\circ} \mathrm{C}$

112 for $30 \mathrm{~min}$. The suspension was spun $\left(3220 \times \mathrm{g}, 10 \mathrm{~min}, 18^{\circ} \mathrm{C}\right)$ and the $10 \mathrm{~mL}$ warm water

113 extract was transferred to a fresh $50 \mathrm{~mL}$ conical tube. Then, $40 \mathrm{~mL}$ of $95 \%$ ethanol was added to

114 the $10 \mathrm{~mL}$ warm water extract, inverted, and allowed to form a precipitate overnight at $-20{ }^{\circ} \mathrm{C}$

115 [7]. Soluble, total carbohydrate content was monitored throughout the purification procedure 
116 (described below, 2.2.3. - 2.2.4.). The precipitate was pelleted by centrifugation $(3220 \times \mathrm{g}, 10$

$117 \mathrm{~min}, 4^{\circ} \mathrm{C}$ ), supernatant discarded, and the pellet was thouroughly resuspended in $10 \mathrm{~mL} 95 \%$

118 ethanol by vigrous pipetting. This process was repeated once more to wash the pellet with $95 \%$

119 ethanol twice in total. After the second ethanol wash, the pellet was resolubilized with $5 \mathrm{~mL}$

120 deionized water. The resolubilized precipitate was enzymatically treated: a simultaneous DNase

121 (Thermo Scientific, \#EN0521) and RNase (Thermo Scientific, \#EN0201) digest was performed

122 for $1 \mathrm{~h}$ at $4{ }^{\circ} \mathrm{C}$, followed by a $90 \mu \mathrm{g} \mathrm{mL} \mathrm{m}^{-1}$ Proteinase $\mathrm{K}$ treatment (Fisher Scientific, BP1700-100)

123 for $2 \mathrm{~h}$ at $4{ }^{\circ} \mathrm{C}$. Then, 4 volumes of $95 \%$ ethanol were added to this aqueous solution and

124 allowed to precipitate overnight at $-20{ }^{\circ} \mathrm{C}$. Two $95 \%$ ethanol washes were performed the

125 following day, and the pellet was resuspended with deionized water to a final volume of $3 \mathrm{~mL}$.

126 This $3 \mathrm{~mL}$ solution transferred into a 2K MWCO Slide-A-Lyzer dialysis cassette (Thermo

127 Scientific, \#87718) and was dialzyed against deionized water for $24 \mathrm{~h}$ at $18{ }^{\circ} \mathrm{C}$ with continuous

128 stir bar mixing. The dialysis volume was $3 \times 0.6 \mathrm{~L}$, where deionized water was replaced at $2 \mathrm{~h}$

129 and $4 \mathrm{~h}$. The dialyzed retentate was passed through a $5 \mathrm{~mL}$ DEAE FF column (GE Healthcare,

130 \#17-515-01) on an ÄKTA start FPLC (GE Healthcare). Protein content was monitored during

131 elution using an A280 detector on the FPLC. A $0-1 \mathrm{M} \mathrm{NaCl}$ gradient was applied using a $1 \mathrm{M}$

$132 \mathrm{NaCl}$ buffer and $5 \mathrm{~mL}$ fractions were collected. Carbohydrate-containing fractions were pooled,

133 frozen in liquid nitrogen, and lyophilized overnight. A polishing step took place by resuspending

134 the lyophilized powder with deionized water to a final volume of $0.5 \mathrm{~mL}$ and applied to a

135 Superdex 75 10/300 GL (GE Healthcare, \#17-5174-01). One mL fractions were eluted using a

136 flow rate of $0.5 \mathrm{~mL} \mathrm{~min}^{-1}$ and carbohydrate enriched fractions pooled, frozen, and lyophilized as

137 described above, which yielded a purified polysaccharide sample used for compositional and 
138 structural analyses. Laminarin from Laminaria digitata was purchased from Sigma (\#L-9634)

139 and was directly used as a control for compositional and structural analyses.

140 2.1.3. Compositional analysis with alditol acetate derivatization and GC/MS

141 Compositional analysis of purified carbohydrate samples was performed using an

142 established GC/MS approach [42]. Briefly, $1.0 \mu \mathrm{g}$ of the internal standard, 3-O-methylglucose,

143 was added to each sample: laminarin, the purified soluble glucan from Phaeodactylum, and the

144 neutral sugar standard (rhamnose, arabinose, ribose, fucose, myo-inositol, mannose, galactose

145 and glucose; $5 \mu \mathrm{g}$ each). Dried samples were hydrolyzed with $250 \mu \mathrm{L} 2 \mathrm{M}$ trifluoroacetic acid

146 (TFA) for $2 \mathrm{~h}$ at $120^{\circ} \mathrm{C}$. After cooling to room temperature (RT), samples were dried under

147 nitrogen gas $\left(\mathrm{N}_{2}\right)$. The dried, hydrolyzed samples were reduced with $200 \mu \mathrm{L} 10 \mathrm{mg} \mathrm{mL}^{-1}$ sodium

148 borodeuteride in 1:1 of $1 \mathrm{M}$ ammonium hydroxide and $95 \%$ ethanol for $2 \mathrm{~h}$ at RT, which was

149 then terminated by adding 4 - 5 drops of glacial acetic acid. After drying the reduced samples

150 under $\mathrm{N}_{2}, 200 \mathrm{uL} 10 \%$ glacial acetic acid in methanol were added, and then were dried under $\mathrm{N}_{2}$.

151 This process was repeated 4 - 5 times. To the completely dried samples, $100 \mu \mathrm{L}$ acetic anhydride

152 was added, incubated at $100{ }^{\circ} \mathrm{C}$ for $1 \mathrm{~h}$, and then were gently dried under $\mathrm{N}_{2}$. Two $\mathrm{mL}$

153 chloroform and $1 \mathrm{~mL}$ deionized water $(\mathrm{v} / \mathrm{v}, 2: 1)$ were added to the acetylated samples to extract

154 the derivatized products by centrifugation $(1000 \times \mathrm{g}, 1 \mathrm{~min}, \mathrm{RT})$. After removing the upper

155 aqueous layers, $1 \mathrm{~mL}$ deionized water was added to the lower organic phase to repeat the

156 extraction 4 more times. The organic phase was gently dried under $\mathrm{N}_{2}$ and resuspended in $50 \mu \mathrm{L}$

157 chloroform for gas chromatography/mass spectrometry (GC/MS) analysis. GC/MS analyses were

158 carried out using a CP 3800 gas chromatograph (Varian) equipped with an MS320 mass

159 spectrometer. Helium was used as the carrier gas with a flow rate of $1 \mathrm{~mL} \mathrm{~min}{ }^{-1}$. The samples

160 were run on a DB 5 column $\left(30 \mathrm{~m} \times 0.20 \mathrm{~mm}\right.$ i.d.). The oven temperature was held at $50{ }^{\circ} \mathrm{C}$ for 
$1611 \mathrm{~min}$ and programmed at $30^{\circ} \mathrm{C} \min ^{-1}$ to $150{ }^{\circ} \mathrm{C}$ and then programmed at $5{ }^{\circ} \mathrm{C} \min ^{-1}$ to $275^{\circ} \mathrm{C}$.

162 Chromatographs were exported to Sigmaplot for analysis.

163 2.1.4. Structural analysis and interpretation with ${ }^{I} H-N M R$

164 Proton NMR spectroscopy at $500 \mathrm{MHz}$ of the glucan dissolved in DMSO- $\mathrm{d}_{6}$ was done at $16580^{\circ} \mathrm{C}$ with a Varian-Inova NMR Spectrometer by using a switchable, $5 \mathrm{~mm}$ broadband probe.

166 The spectral window was $8 \mathrm{kHz}$ and the acquisition time was 2.0 seconds. 32 signal averaging

167 transients were applied with a 22.5 degree tip angle in a simple one-pulse-acquire sequence.

168 There was a relaxation delay of 10 seconds between transients. The free induction decay, FID,

169 was Fourier transformed and the resulting spectral data resolution was $0.5 \mathrm{~Hz}$ per point. The

170 DMSO- $\mathrm{d}_{5} \mathrm{H}_{1}$ impurity was used as an internal spectral reference set to $2.5 \mathrm{ppm}$. Peaks resolved in

171 the spectra were annotated based on their chemical shift and the area under the annotated peaks

172 was determined to infer structural properties of the $\beta-1,3$ glucan as previously described [43].

173

174 2.2. Diel light regime experiment

175 2.2.1. Growth conditions, medium, and cell harvesting

176 Phaeodactylum was grown in medium as described in 2.1.1 but instead maintained in 125

$177 \mathrm{~mL}$ Erlenmeyer flasks. Triplicate cultures were grown at $18{ }^{\circ} \mathrm{C}$ and were constantly mixed on a

178 shaking platform at $120 \mathrm{rpm}$. Light was provided in a 16:8 day/night cycle, where daytime

179 irradiance was maintained at $325 \pm 15 \mu$ mol photons $\mathrm{m}^{-2} \mathrm{~s}^{-1}$ (LI-COR light meter, LI-250A, $2 \pi$

180 sensor). Phaeodactylum cells $\left(\sim 1.0 \times 10^{8}\right)$ were harvested by centrifugation $(3220 \times \mathrm{g}, 10 \mathrm{~min}$,

$18118{ }^{\circ} \mathrm{C}$ ) in $50 \mathrm{~mL}$ conical tubes. The supernatant was discarded and the pellet was stored at $-80{ }^{\circ} \mathrm{C}$

182 until warm water extraction.

183 2.2.2. Warm water extraction of soluble carbohydrates 
We followed the warm water extraction described by Chiovitti et al. [10], but at a higher

185 incubation temperature. Frozen cell pellets were thawed on the day of analysis, suspended in 1.5

$186 \mathrm{~mL}$ deionized water $(18.2 \mathrm{~m} \Omega)$, placed in microcentrifuge tubes, and incubated at $50{ }^{\circ} \mathrm{C}$ for 15

187 min to extract soluble carbohydrates. Insoluble carbohydrates and soluble carbohydrates were

188 separated by centrifugation $(20,000 \times \mathrm{g}, 5 \mathrm{~min}, \mathrm{RT})$, and the $1.5 \mathrm{~mL}$ soluble fraction was

189 transferred to a new microcentrifuge tube.

190 2.2.3. Sulfuric acid hydrolysis of carbohydrate fractions

191 Sulfuric acid hydrolysis and quantification of carbohydrates were performed as described

192 by Van Wychen and Laurens [40], with several changes to the protocol to enable quantification

193 of multiple carbohydrate fractions. Immediately after the warm water extraction described above,

194 the insoluble pellet was resuspended with $1 \mathrm{~mL}$ deionized water and transferred to a labeled,

195 glass microwave vial (VWR, \#89079-404). A $1 \mathrm{~mL}$ aliquot of the soluble fraction was also

196 transferred to a labeled, glass microwave vial. The remaining $0.5 \mathrm{~mL}$ soluble carbohydrate

197 sample was reserved at $4{ }^{\circ} \mathrm{C}$ until quantification. $250 \mu \mathrm{L}$ sulfuric acid $(72 \%(w / w)$; Fluka,

198 \#00647) was added to each sample, capped (Wheaton, \#224100-203), vortexed, and incubated at

$199 \mathrm{RT}$ for $1 \mathrm{~h}$. After the incubation, the tubes were uncapped and $6 \mathrm{~mL}$ deionized water was added

200 to each sample, bringing the final volume to $7.25 \mathrm{~mL}$. The vials were recapped, crimp-sealed

201 with $20 \mathrm{~mm}$ aluminum caps (Wheaton, \#224193-01), and placed in an autoclavable rack in a

202 pressure cooker for $1 \mathrm{~h}\left(121{ }^{\circ} \mathrm{C}, 83 \mathrm{kPa}\right)$. After the pressure equalized, vials were removed from

203 the pressure cooker and cooled to RT. A $2 \mathrm{~mL}$ aliquot was taken from each acidified sample and

204 placed in a labeled $50 \mathrm{~mL}$ conical tube and was neutralized $(\mathrm{pH} 6-\mathrm{pH}$ 8) with calcium

205 carbonate (Sigma-Aldrich, \#C6763), verified by placing a few drops of solution on $\mathrm{pH}$ indicator

206 strips (MColorpHast, EMD Millipore, \#109535). Neutralized solution was then filtered through a 
207 nylon filter $(0.2 \mu \mathrm{m}$ pore size; Fisher, \#09-719-006) to remove precipates. Neutralized, filtered

208 solutions were stored at $4{ }^{\circ} \mathrm{C}$ and used for quantification within $24 \mathrm{~h}$.

209 2.2.4. Quantification of carbohydrate fractions

210 Quantification of carbohydrates using the MBTH method was performed as described

211 previously [40], with some modifications outlined below. A $250 \mu \mathrm{L}$ sample was added to a glass

212 vial (Pyrex, \#9820-10), to which $250 \mu \mathrm{L} 0.5 \mathrm{M} \mathrm{NaOH}$ and $500 \mu \mathrm{L}$ of a freshly prepared 1:1 (v/v)

213 solution of $3 \mathrm{mg} \mathrm{mL}^{-1}$ MBTH:1 $\mathrm{mg} \mathrm{mL}^{-1}$ dithiothreitol (Sigma-Aldrich, \#129739; Sigma-Aldrich

214 \#D0632) were added, in that order. Glass vials were capped, vortexed, and incubated at $80{ }^{\circ} \mathrm{C}$ for

$21515 \mathrm{~min} .500 \mu \mathrm{L}$ ferric solution $(0.5 \%$ (w/v) ammonium iron (III) sulfate (Acros Organics,

$216 \# 205880500), 0.5 \%$ (w/v) sulfamic acid (Sigma-Aldrich, \#242772) in $0.25 \mathrm{M} \mathrm{HCl}$ ) was added to

217 each sample on the heat block. Samples were vortexed, removed from the heat block and

218 allowed to cool for $15 \mathrm{~min}$ at RT. These samples were diluted with $1250 \mu \mathrm{L}$ deionized water, and

$2191 \mathrm{~mL}$ was transferred to $1 \mathrm{~cm}$ pathlength acrylic cuvettes to determine absorbance at $620 \mathrm{~nm}$.

220 Carbohydrate concentrations were determined from a standard curve of glucose concentrations

221 ranging from (0 to 0.050$) \mathrm{mg} \mathrm{mL}^{-1}$ prepared in parallel with each set of experimental samples.

222 The soluble fraction that was hydrolyzed, neutralized, and filtered (see 2.3.4.) generated a

223 value for total soluble carbohydrates. Similarly, the insoluble fraction that was hydrolyzed,

224 neutralized, and filtered generated a value for total insoluble carbohydrates. The soluble fraction

225 that was reserved after warm water extraction (see 2.3.3.) generated a value for soluble, reducing

226 carbohydrates only. Subtracting the concentration of soluble, reducing carbohydrates from

227 soluble, total carbohydrates yielded soluble, nonreducing carbohydrates. Dividing these

228 concentrations by the total number of cells harvested for the respective experimental sample 
229 yields carbohydrate fractions on a per cell basis. All carbohydrate fractions are reported as

230 average pg glucose equivalents (g.e.) per cell.

232 2.3. Nitrate depletion experiment

\section{2.3.1. Growth conditions and media}

234 Phaeodactylum was grown in $1 \mathrm{~L}$ Roux flasks in $0.8 \mathrm{~L}$ of of artificial seawater (Instant

235 Ocean, $35 \%$ salinity). Nutrients were added as described by Guillard [41], except for the nitrate

236 deplete media where nitrate was omitted. Silica was omitted from the media. Light was provided

237 in a 12:12 day/night cycle, where daytime irradiance was set at $420 \pm 20 \mu \mathrm{mol}$ photons $\mathrm{m}^{-2} \mathrm{~s}^{-1}$

238 (LI-COR light meter, LI-250A, $2 \pi$ sensor). Five replicate cultures were grown at $18{ }^{\circ} \mathrm{C}$ and

239 were mixed by sparging with $1 \mathrm{~L} \mathrm{~min}^{-1}$ air. Cultures were maintained in exponential growth for

240 at least two days prior to the start of the experiment with serial dilutions. The experiment was

241 carried out for 4 days. Harvests extracted appropriate volumes (described below) to quantify:

242 carbohydrates, total organic carbon and total nitrogen, chlorophyll, and triacylglycerol. Nitrate

243 replete cultures were harvested at dusk and dawn at 0 and 0.5 days. Culture media was

244 exchanged at 0.6 days by spinning down $400 \mathrm{~mL}$ of culture $\left(3220 \times \mathrm{g}, 10 \mathrm{~min}, 18^{\circ} \mathrm{C}\right)$, washing

245 pellets twice with filtered artificial seawater, and resuspending the algae pellets in $400 \mathrm{~mL}$ nitrate

246 deplete media. Nitrate deplete cultures were harvested at dusk and dawn at 2.5, 3.0, 3.5, and 4.0

247 days. Flow cytometry and chorophyll $a$ fluorescence measurements were taken every $12 \mathrm{~h}$,

248 corresponding to dusk and dawn during the entire nitrate depletion experiment.

249 2.3.2. Flow cytometry: cell counts, chlorophyll autofluorescence and forward scattering

250 We used an Accuri C6 flow cytometer (BD) to determine cell density, chlorophyll

251 autofluorescence per cell, and forward scattering per cell. $2 \mathrm{~mL}$ of culture were passed through a 
$25230 \mu \mathrm{m}$ filter (Myltenyi Biotec, \#130-101-812) to remove any debris prior to analysis and diluted

253 in filtered artificial seawater to maintain less than 2000 detected events $\mathrm{sec}^{-1}$. The flow rate was

$25435 \mu \mathrm{L} \mathrm{min}{ }^{-1}$, and the core size was $16 \mu \mathrm{m}$. Relative chlorophyll autofluoresence was determined

255 by excitation with a $488 \mathrm{~nm}$ laser (emission $>670 \mathrm{~nm}$ ). Phaeodactylum cell counts $\mu \mathrm{L}^{-1}$ were

256 determined by gating for particles with chlorophyll autofluoresence.

257 2.3.3. Nitrate depletion experiment cell harvesting

258 Cells harvested during nitrate depletion did not adequately pellet in $50 \mathrm{~mL}$ conical tubes;

259 therefore, we collected cells by filtration. About $2.0 \times 10^{8}$ Phaeodactylum cells were harvested

260 by filtering a culture volume (ranging from 50 to $150 \mathrm{~mL}$, dependent on cell density) onto a

261 polycarbonate filter (EMD Millipore, \#ATTP02500). Filters were then placed in a beaker and

262 cells were removed from the filter by repeated pipetting with $2 \mathrm{~mL}$ filtered artificial seawater.

263 The $2 \mathrm{~mL}$ suspension was transferred into two $1 \mathrm{~mL}$ aliquots in microcentrifuge tubes. These

264 resuspended cells were pelleted by centrifugation $\left(20,000 \times \mathrm{g}, 10 \mathrm{~min}, 18^{\circ} \mathrm{C}\right)$ and the

265 supernatant was meticulously removed. These pellets were stored at $-80^{\circ} \mathrm{C}$ until further

266 processing. One pellet was used for quantification of carbohydrate fractions (described above)

267 and the other was used for triacylglycerol quantification (described below).

268 2.3.4. Total organic carbon and total nitrogen quantification

269 Total organic carbon (TOC) and total nitrogen (TN) were determined using a Shimadzu

270 TOC-L Laboratory TOC Analyzer. TOC was determined by the difference method, where

271 inorganic carbon (IC) was subtracted from total carbon (TC) to yield TOC. Ten $\mathrm{mL}$ of culture

272 was harvested at dusk and dawn during the nitrate depletion experiment and placed into $50 \mathrm{~mL}$

273 conical tubes. These samples were pelleted by centrifugation $\left(12000 \times \mathrm{g}, 15 \mathrm{~min}, 18^{\circ} \mathrm{C}\right)$ and

274 washed once with filtered artificial seawater, then resuspsended in $10 \mathrm{~mL}$ deionized water. A 1 
$275 \mathrm{~mL}$ aliquot was taken to determine cell density by flow cytometry. The remaining $9 \mathrm{~mL}$ was

276 frozen at $-80{ }^{\circ} \mathrm{C}$ until the day of analysis. All glass and plasticware was acid-washed with $10 \%$

$277 \mathrm{HCl}$ prior to use to remove any residual organic carbon. On the day of analysis, the $9 \mathrm{~mL}$

278 samples were thawed to room temperature. Eight $\mathrm{mL}$ was transferred into TOC glass vials and

279 were diluted to a final volume of $40 \mathrm{~mL}$ with deionized water. The injection volume was $100 \mu \mathrm{L}$,

280 and the instrument perfomed technical replicates of the injection such that duplicate values of

281 less than $10 \%$ difference were used to determine TC, IC and TN for each sample. TC, IC, and

282 TN concentrations were then divided by the number of cells in the $8 \mathrm{~mL}$ sample to determine

283 TOC and TN per cell.

284 2.3.5. Chlorophyll quantification

$28510 \mathrm{~mL}$ of Phaeodactylum cells were collected and stored at $-80^{\circ} \mathrm{C}$. Samples were thawed

286 the day of analysis and filtered through a glass fiber filter (EMD Millipore, AP2001300).

287 Pigments were extracted from glass filters by resuspension with $1 \mathrm{~mL}$ methanol, vortexed for 15

$288 \mathrm{~s}$, and incubated in the dark for $15 \mathrm{~min}$. Cell debris and residual glass fibers were removed by

289 centrifugation $\left(15000 \times \mathrm{g}, 10 \mathrm{~min}, 4^{\circ} \mathrm{C}\right)$ and the pigment-containing supernatants were pipetted

290 into disposable acrylic cuvettes for analysis. No visible color remained on the filters. Chlorophyll

$291 a$ and chlorophyll $c_{1}+c_{2}$ were determined using established spectrophotometric methods [44].

292 Chlorophyll $a$ per cell was determined by dividing the chlorophyll $a$ concentration by the total

293 number of cells in the harvested sample, calculated from cell density and the volume extracted.

294 2.3.6. Monitoring neutral lipids with BODIPY and triacylglycerol quantification

295 Neutral lipid accumulation patterns were observed during the nitration depletion

296 experiment using the fluorescent dye BODIPY $(E x=503 \mathrm{~nm}, \mathrm{Em}=512 \mathrm{~nm}$, Life Technologies,

297 \#D-2184). A single solution of $100 \mu \mathrm{g} \mathrm{mL}^{-1}$ BODIPY in dimethyl sulfoxide was prepared and 
298 divided into single-use aliquots stored at $-80{ }^{\circ} \mathrm{C}$ for all timepoints during the nitrate depletion

299 experiment to minimize variability of the dye from handling and freeze-thaw cycles. Samples

300 were prepared for flow cytometry as described above. A BODIPY aliquot was thawed

301 immediately before analysis and $6.7 \mu \mathrm{L}$ of the BODIPY solution was added to a $1 \mathrm{~mL}$ filtered

302 culture sample, yielding a final concentration of $0.067 \mu \mathrm{g} \mathrm{mL}^{-1}$ [45]. Samples were vortexed for

$3033 \mathrm{~s}$, incubated in the dark for $4 \mathrm{~min}$, then briefly vortexed again prior to analysis by flow

304 cytometry. BODIPY fluorescence was determined by excitation with a $488 \mathrm{~nm}$ laser and

305 collected by a 533/30 nm bandpass filter, enabling quantification of mean BODIPY fluoresence

306 per cell.

307 Triacylglycerols (TAG) were quantified from a neutral lipid extraction, as described

308 previously [46]. Briefly, cell pellets were prepared for analysis (see 2.3.2) and neutral lipids from

309 these pellets were extracted via solid phase extraction, as described previously [47]. Eluted TAG

310 samples were placed in a random order on a silica plate for thin layer chromatography and

311 quantification. TAG was quantified from a standard curve of tripalmitin (1,2,3-trihexadecanoyl-

312 glycerol, TAG 16:0 16:0 16:0, Avanti Polar Lipids, \#111000) using ImageJ, version 1.48

313 (http://imageJ.nih.gov/ij/). Values reported as tripalmitin equivalents (t.e.) per cell.

\section{$314 \quad$ 2.3.7. Chlorophyll a fluorescence measurements}

315 Five $\mathrm{mL}$ of cell culture was harvested at dawn and dusk timepoints during the nitrate

316 depletion experiment for variable chlorophyll fluorescence measurements to determine $F_{v} / F_{m}$

317 with a Walz DUAL-PAM 100 fluorometer. Samples were acclimated at $9 \mu \mathrm{mol}$ photons $\mathrm{m}^{-2} \mathrm{~s}^{-1}$

318 for $30 \mathrm{~min}$ to relax nonphotochemical quenching prior to $F_{v} / F_{m}$ measurement [48]. Samples were

319 filtered onto a glass fiber filter (EMD Millipore, AP2001300) for measurement. Measuring light 
320 intensities were adjusted so that the baseline fluoresence was approximately $0.20 \mathrm{~V}$ prior to the

321 saturating light pulse.

$322 \quad$ 2.4. Statistical analysis

323 A paired student's t-test $(\alpha=0.05)$ was used to compare quantities of carbohydrate pools

324 between dawn and dusk. For the nitrate depletion timecourse, a repeated measures one-way

325 ANOVA $(\alpha=0.05)$ followed by a Tukey's HSD post-hoc test was performed to describe

326 statistically different groups. All statistical analysis was performed using Sigmaplot (Systat

327 Software).

328

$329 \quad$ 3. Results

330 3.1. Analytical chemistry of soluble polysaccharide extracted from Phaeodactylum

331 Three major carbohydrate fractions were resolved with our method: insoluble; soluble,

332 reducing; and soluble, total carbohydrates (Figure 1). A critical methodological assumption is

333 that chrysolaminarin is present in the soluble, nonreducing carbohydrate determined from

334 subtracting soluble, reducing sugars from soluble, total carbohydrates. To test this assumption,

335 we set out to analyze the soluble, nonreducing carbohydrate. We tested a range of warm water

336 temperatures in order to extract soluble carbohydrates from Phaeodactylum. We found that the

337 greatest values of soluble carbohydrate were found at extraction temperatures above $50{ }^{\circ} \mathrm{C}$,

338 which therefore represents an appropriate soluble carbohydrate extraction temperature for

339 Phaeodactylum (Supplemental Figure 1).

340 We enriched a Phaeodactylum polysaccharide from this soluble extract for compositional

341 and structural analysis. The first round of precipitation contained $72 \mathrm{mg}$ glucose equivalents

342 (g.e.) carbohydrate from the combined $4 \mathrm{~L}$ batch culture as determined by MBTH quantification 
343 of soluble, total carbohydrate. $57 \mathrm{mg}$ g.e. of soluble, total carbohydrate remained after enzymatic

344 digests, ethanol precipitation, and dialysis, and $45 \mathrm{mg}$ g.e. remained after two rounds of FPLC

345 purification (Supplemental Figure 2). FPLC fractions were pooled, dialyzed and lyophilized,

346 yielding a dry weight of $42.1 \mathrm{mg}$ of material that was $97.6 \%$ pure carbohydrate by dry weight.

347 The final yield of purified polysaccharide was $58 \%$ of the initial soluble extract quantity, with

348 most of the losses occurring during the early ethanol precipitation steps prior to FPLC

349 purification.

350 Monomer analysis of the purified polysaccharide was determined via GC/MS of alditol

351 acetate sugar derivatives (Figure 2A). Our positive control, laminarin, was comprised of glucose

352 (Figure 2B). The Phaeodactylum purified polysaccharide was composed of glucose (Figure 2C).

353 The internal standard, 3-O-methylglucose, was observed in all samples.

354 We also performed structural analysis of the purified polysaccharide using ${ }^{1} \mathrm{H}-\mathrm{NMR}$. This

355 analysis relied on existing annotations and chemical shift assignments [43]. A model $\beta$-glucan

356 with individually labeled anhydrous glucose units (AGU) is shown in Figure 3A for a structural

357 reference. Protons from each of these unique anhydrous glucose units are resolved in the $\beta$ -

358 glucan ${ }^{1} \mathrm{H}-\mathrm{NMR}$ spectra as a doublet at an expected chemical shift. The spectra of laminarin

359 (Figure 3B) and Phaeodactylum purified polysaccharide (Figure 3C) are presented. The largest

360 annotated doublet corresponded to the backbone chain (BC) at $\sim 4.54 \mathrm{ppm}$ in both spectra. A

361 doublet for the terminal side chain AGU is not observed in the Phaeodactylum soluble

362 polysaccharide, indicating a single AGU for the side chain. Analysis of the integrals of the

363 doublets permits structural inference of the glucans (Table 1). Laminarin has 28 glucose residues

364 as determined by degree of polymerization (DP) with a degree of branching (DB) of 0.063 .

365 These values are higher than the Phaeodactylum purified polysaccharide with 17 glucose 
366 residues and a DB of 0.015 . The number of branches per each molecule can be estimated by

367 multiplying DP and DB. Laminarin has about 2 branches per polysaccharide while only about

368 one in four of the Phaeodactylum purified polysaccharide has a side chain.

370 3.2. Accumulation of carbohydrate fractions differs in day/night cycles

371 We compared our three experimentally resolved carbohydrate fractions at dawn and dusk

372 (Figure 4). There was no significant change of insoluble carbohydrates per cell between dawn

373 and dusk $(\mathrm{p}=0.80)$. A significant decrease of soluble, reducing carbohydrates was observed

374 between dawn and dusk $(\mathrm{p}<0.05)$. However, the largest relative and absolute differences

375 observed were for soluble, nonreducing carbohydrates. This component dropped from $1.56 \pm$

3760.25 pg g.e. per cell at dusk to $0.06 \pm 0.03$ pg g.e. per cell at dawn $(n=3, p<0.05)$.

377 3.3. Nitrate depletion cell physiology and carbon partitioning into carbohydrate fractions

378 We investigated cell physiology during the first 3 days of nitrate depletion. Cell densities 379 increased in nitrate replete medium, but the increase of cell densities stopped 2 days following 380 transfer into nitrate deplete medium (Figure 5A). The forward scatter (FSC) measured by flow

381 cytometry is a proxy for cell size, since the relationship between FSC and cell size is not linearly

382 proportional for pennate diatoms [49]. The FSC of Phaeodacylum oscillated in nitrate replete

383 medium, with a maximum at dusk and a minimum at dawn (Figure 5B). The oscillation pattern

384 ceased after 2 days in nitrate deplete medium.

385 TOC per cell significantly decreased in the dark under nitrate replete conditions but the

386 daily increase in TOC was not observed in nitrate deplete conditions (Figure 5C, $\mathrm{p}<0.05$ ). The

387 decrease of TN per cell in nitrogen replete medium at night was small but statistically significant 
388 (Figure 5D, $\mathrm{p}<0.05$ ). TN per cell decreased during nitrogen deprivation to about $0.44 \mathrm{pg} \mathrm{TN}$ per 389 cell $(\mathrm{p}<0.05)$.

$390 \quad \mathrm{~F}_{\mathrm{v}} / \mathrm{F}_{\mathrm{m}}$, a measurement of the quantum efficiency of photosystem II [50], dropped from 0.6

391 to 0.2 after two days of nitrate deprivation (Figure 5E, p < 0.05). Chlorophyll $a$ was maintained

392 between $0.13-0.14$ pg per cell in nitrate replete media but decreased after $2-3$ days without

393 nitrate (Figure 5F, $\mathrm{p}<0.05$ ). No significant difference was observed for the chlorophyll $c_{1}+c_{2}$ :

394 chlorophyll $a$ ratio at any timepoint during the experiment (Figure 5G, p $=0.19$ ).

395 We observed the partitioning of carbon within different carbohydrate fractions and neutral

396 lipids during nitrate depletion. Soluble, nonreducing carbohydrate dropped significantly in the

397 dark from $2.32 \mathrm{pg}$ g.e. per cell to $0.36 \mathrm{pg}$ g.e. per cell but remained between 1.04 and $1.34 \mathrm{pg}$

398 g.e. per cell $2-3$ days after nitrate removal (Figure $6 \mathrm{~A}, \mathrm{p}<0.05$ ). Soluble, reducing sugars also

399 significantly decreased at night in nitrate replete medium (Figure 6B, p < 0.05). Soluble,

400 reducing sugars accumulated at slightly lower quantities after $2-3$ days in nitrate deplete

401 medium than the maximum in nitrate replete medium. A small, significant drop of insoluble

402 carbohydrate was observed in nitrogen replete growth between dawn and dusk, but also remained

403 at a steady level in nitrate deplete conditions, between 0.82 and 0.86 pg g.e. per cell (Figure 6C,

$404 \mathrm{p}<0.05)$. The amount of soluble, reducing sugars did not change throughout nitrogen starvation

405 (Figure 6D, $\mathrm{p}<0.05$ ).

406 BODIPY fluorescence per cell, which is commonly used as an indicator of neutral lipid

407 content, oscillated with maxima at dusk and minima at dawn for the entire experiment (Figure

$4086 \mathrm{E}, \mathrm{p}<0.05)$. However, quantification of TAG per cell suggested that the oscillating neutral lipid

409 abundance is limited to nitrate replete conditions (Figure 6F, $\mathrm{p}<0.05$ ). During nitrate starvation,

410 TAG per cell accumulated to about $6 \mathrm{pg}$ t.e. per cell and did not differ between dawn and dusk. 
Soluble, nonreducing sugars and TAG were normalized for their mass-fraction of carbon,

4120.4 units (glucose, $\mathrm{C}_{6} \mathrm{H}_{12} \mathrm{O}_{6}$ ) and 0.76 units (tripalmitin, $\mathrm{C}_{51} \mathrm{H}_{98} \mathrm{O}_{6}$ ) respectively (Figure 7).

413 Carbon partitioning into soluble, nonreducing sugar was comparable to triacylglycerols at dusk

414 under nitrate replete conditions, accounting for $6.9 \%$ and $10 \%$, respectively. However, after $2-$

4153 days of nitrate removal, soluble, nonreducing carbohydrate only represents about $5.5 \%$ of

416 TOC whereas TAG dominates carbon partitioning, accounting for about $45 \%$ of TOC.

418 4. Discussion

$420 \quad$ 4.1 Soluble, nonreducing carbohydrate fraction contains chrysolaminarin

423 of glucose, with limited branching [7]. Our extraction workflow began by extracting saccharides

424 from whole cells at $50{ }^{\circ} \mathrm{C}$. This bulk extract does not contain any signature components of

425 Phaeodactylum extracellular polysaccharides, which are composed of mannose and glucose with

426 complex linkages and branching [51]. Instead, our isolated glucan from the soluble extract was

427 entirely composed of glucose (Figure 3), agreeing with past studies of chrysolaminarin [7, 52].

428 The purified glucan exhibited ${ }^{1} \mathrm{H}-\mathrm{NMR}$ signatures characteristic of $\beta-1,3$ glucans (Figure 4).

429 However, purification accounted for a loss of $15 \mathrm{mg}$ g.e of. uncharacterized glucan from

430 dialyzed retentate to purified glucan, or about $26 \%$. It is possible that this lost fraction contains

431 some alternative soluble glucose polymer whose identity is unknown.

432 The ${ }^{1} \mathrm{H}-\mathrm{NMR}$ spectrum also permits inference of structural characteristics of the glucan.

433 The integrated, annotated peaks can be used to determine the degree of polymerization (DP) and 
434 the degree of branching (DB) [43]. Structural features significantly vary by diatom species, even

435 between closely related organisms [11, 51-53]. We found that Phaeodactylum's chrysolaminarin

436 is smaller and lightly branched compared to laminarin, which is consistent with earlier

437 observations. [7] (Table 1). The structure of the $\beta-1,3 / \beta-1,6$ glucan means that for an average

438 molecule of chrysolaminarin, 16 of 17 glucose units are non-reducing sugars (94\%) (Table 1).

439 Compositional and structural analysis of the Phaeodactylum glucan supports our assumption that

440 the soluble, nonreducing carbohydrate fraction contains chrysolaminarin. We recommend similar

441 analytical steps be taken when applying this method to species other than Phaeodactylum.

442 Chrysolaminarin, is thought to serve as a respiratory substrate in the dark [46]. Our

443 results demonstrate that soluble, nonreducing carbohydrate dramatically decreases between dusk

444 and dawn, especially relative to the other carbohydrate pools (Figure 4). We also found this

445 fraction significantly increased with growth irradiance (Supplemental Figure 3). These

446 observations further support our assertion that the soluble, nonreducing fraction is mostly

447 chrysolaminarin. We note that our values are lower than those found by Chauton et al. [18] from

448 Phaeodactylum cells entrained to day/night cycles. The extraction methods used by Chauton et

449 al. [18], which contains dilute sulfuric acid, have been shown to extract other non-glucose

450 containing carbohydrates in addition to chrysolaminarin [53] and the colorimetric assay utilized

451 to quantify reducing sugars (phenol-sulfuric acid) provides poor precision for a complex mixture

452 of sugars [55]. In light of our analytical chemistry and physiology results for the soluble,

453 nonreducing carbohydrate, we suggest that this fraction represents a good proxy for quantifying

454 chrysolaminarin and hereafter refer to this as chrysolaminarin.

455

4564.2 Repartitioning carbohydrate pools during nitrogen starvation. 
We sought to understand the dynamics of chrysolaminarin storage in response to nitrogen

458 starvation. Our biochemistry and photophysiology data show a daily oscillation in

459 Phaeodactylum cell composition and size prior to exchange into nitrogen free media. Cell

460 density increased (Figure 5A) and cell size (assumed to be proportional to forward scatter)

461 oscillated depending on time of day (Figure 5B). The quantum efficiency of photosystem II

462 remained high (Figure 5E), as did chlorophyll $a$ per cell (Figure 5F). We, and others, have

463 previously observed synchronized cell division in Phaeodactylum growing in a day/night cycle

$464[18,46]$. An increase of cell TOC during the day, particularly as chrysolaminarin and TAG,

465 (Figure 6) provides carbon skeletons that support cell division and heterotrophic metabolism at

466 night during nutrient replete growth. The consumption of these substrates in the dark to fuel

467 heterotrophic metabolism has been described previously [46, 56].

468 The daily oscillation observed in nutrient replete conditions ceased in nitrogen-deplete

469 conditions. This was observed after $2-4$ days in nitrate-free medium. Increases in cell

470 concentration slowed (Figure 5A) and oscillations in cell size stopped (Figure 5B). While TN

471 (Figure 5D), $\mathrm{F}_{\mathrm{v}} / \mathrm{F}_{\mathrm{m}}$ (Figure 5E), and chlorophyll $a$ (Figure 5F) dramatically decreased, the

472 chlorophyll $c_{1}+c_{2}$ : chlorophyll $a$ ratio did not change (Figure 5G), in agreement with previous

473 nitrate starvation observations [57].

474 The patterns of carbon partitioning between carbohydrate fractions and TAG during

475 nitrogen starvation were unforeseen. The dusk/dawn cellular content of carbohydrate did not

476 change during nitrogen starvation and did not increase relative to nutrient replete growth (Figure

477 6). This was also observed for each experimentally resolved carbohydrate pool, including the

478 cellular content of chrysolaminarin (Figure 6B, timepoints 4-6) which only represented $5.5 \%$ of

479 total cellular carbon during nitrogen limitation (Figure 7). TAG content reached its highest 
480 values on a per cell basis (Figure 6F) and also as a total fraction of the TOC (Figure 7). These

481 data show that TAG, not chrysolaminarin, is the primary repository of storage carbon for

482 Phaeodactylum during nitrate starvation in day:night cycles.

483 While it has been determined that total carbohydrate in Phaeodactylum decreases during

484 nitrate starvation $[19,56]$, the dynamics of individual carbohydrate pools have previously only

485 been inferred through proteomics and transcriptomics. For instance, Hockin et al. [24] performed

486 a comparative proteomics experiment at the onset of nitrogen starvation, where they observed a

487 variety of enzymes predicted to participate in carbohydrate metabolism significantly changed.

488 Some of the proteins that increased in relative abundance were glycolysis-specific, suggesting a

489 net shift of carbon from chrysolaminarin reserves into free sugars for metabolism. Transcripts for

490 glycolytic enzymes also increase in abundance during nitrate depletion [19, 26, 35]. Mus et al.

491 [59] also noted an increased abundance of transcripts that are bioinformatically predicted to be

492 related to chrysolaminarin metabolism during nitrate starvation. We note that all experimentally

493 resolved carbohydrate fractions decreased during $\mathrm{N}$-starvation in our study so we posit that some

494 of these transcripts might be associated with the metabolism of insoluble carbohydrates.

495 One proposed strategy to enhance lipid productivity in algae is to interfere with

496 polysaccharide synthesis [5]. Indeed, photoheterotrophically grown Chlamydomonas strains that

497 are unable to produce starch greatly increase the amount of cellular carbon in TAG [31, 32]. This

498 change in carbon partitioning may be further enhanced by nitrogen deprivation, when TAG is

499 significantly accumulated [4]. We found that Phaeodactylum only accumulates $4.9-6.0 \%$ of

500 cellular carbon as chrysolaminarin during nitrate starvation, a relatively small fraction compared

501 to the TAG accumulation of $43-50 \%$ of cellular organic carbon (Figure 7). We note that a large

502 proportion of cellular carbon is used in protein and structural lipids [46], but we did not quantify 
503 those pools in this study. Therefore, the rational engineering strategy of manipulating storage

504 carbohydrate metabolism to increase TAG productivity in Phaeodactylum might not be

505 appropriate. However, it is important to note that the accumulation of soluble carbohydrate

506 varies significantly by algal species [60]. For instance, Skelotonema costatum accumulated

507 soluble carbohydrate during nitrate depletion in a diel light regime [61]. Additionally, $\mathrm{N}$-starved

508 Isochysis sp. accumulated total carbohydrate without daily oscillations compared to N-replete

509 cultures [25], but it is unclear how much of the observed carbohydrate was chrysolaminarin in

510 either of these studies. We caution that careful attention to species-specific physiology and

511 growth conditions must be made when predicting the potential yield changes associated with the

512 engineering of metabolism.

513

\section{$514 \quad$ 5. Conclusions}

515 We report a method that enables parallel characterization of insoluble; soluble, reducing;

516 and soluble, nonreducing carbohydrates, representing an improvement over existing total

517 carbohydrate assays. We have established that the soluble, nonreducing carbohydrate resolved by

518 our MBTH-based method contains chrysolaminarin. Quantification of chrysolaminarin in

519 parallel with other carbohydrate pools is a valuable addition to the biochemical toolkit available

520 for investigating diatom metabolism. We found that high accumulation of chrysolaminarin in

521 Phaeodactylum requires nutrient replete conditions, high irradiance, and occurs at dusk in a diel

522 light regime. We illustrated the utility of this method by showing that: 1) chrysolaminarin

523 accumulates at the end of the day and is consumed by dawn and 2) chrysolaminarin is not

524 preferentially accumulated during nitrogen limitation. So, we stress that estimates of carbon

525 partitioning to biofuel precursors should be made on cultures grown in day/night cycles. We also 
526 suggest that rerouting of carbon flux away from chrysolaminarin reserves is not the most prudent

527 biological engineering strategy for maximizing TAG productivity in this organism. 


\section{Acknowledgements}

529

530 This research was supported by the Department of Energy, Office of Science, Biological and

531 Environmental Sciences, by grant DOE-DE-SC0008595 to G.P.. M.A.C. was supported by an

532 NSF-GRFP fellowship. D.J. was supported by Fondation Bettencourt Schueller. 


\section{References}

535 [1] R.J. Geider, E.H. Delucia, P.G. Falkowski, A.C. Finzi, J.P. Grime, J. Grace, T.M. Kana, J. La

536 Roche, S.P. Long, B.A. Osborne, T. Platt, I.C. Prentice, J.A. Raven, W.H. Schlesinger, V.

537 Smetacek, V. Stuart, S. Sathyendranath, R.B. Thomas, T.C. Vogelmann, P. Williams, F.I.

538 Woodward, Primary productivity of planet earth: biological determinants and physical

539 constraints in terrestrial and aquatic habitats, Global Change Biology, 7 (2001) 849-882.

540 [2] C. Wilhelm, C. Büchel, J. Fisahn, R. Goss, T. Jakob, J. LaRoche, J. Lavaud, M. Lohr, U.

541 Riebesell, K. Stehfest, K. Valentin, P.G. Kroth, The Regulation of Carbon and Nutrient

542 Assimilation in Diatoms is Significantly Different from Green Algae, Protist, 157 (2006) 91-124.

543 [3] E.V. Armbrust, J.A. Berges, C. Bowler, B.R. Green, D. Martinez, N.H. Putnam, S. Zhou,

544 A.E. Allen, K.E. Apt, M. Bechner, M.A. Brzezinski, B.K. Chaal, A. Chiovitti, A.K. Davis, M.S.

545 Demarest, J.C. Detter, T. Glavina, D. Goodstein, M.Z. Hadi, U. Hellsten, M. Hildebrand, B.D.

546 Jenkins, J. Jurka, V.V. Kapitonov, N. Kröger, W.W.Y. Lau, T.W. Lane, F.W. Larimer, J.C.

547 Lippmeier, S. Lucas, M. Medina, A. Montsant, M. Obornik, M.S. Parker, B. Palenik, G.J.

548 Pazour, P.M. Richardson, T.A. Rynearson, M.A. Saito, D.C. Schwartz, K. Thamatrakoln, K.

549 Valentin, A. Vardi, F.P. Wilkerson, D.S. Rokhsar, The Genome of the Diatom Thalassiosira

550 Pseudonana: Ecology, Evolution, and Metabolism, Science, 306 (2004) 79-86.

551 [4] H. Abida, L.-J. Dolch, C. Meï, V. Villanova, M. Conte, M.A. Block, G. Finazzi, O. Bastien,

552 L. Tirichine, C. Bowler, F. Rébeillé, D. Petroutsos, J. Jouhet, E. Maréchal, Membrane

553 Glycerolipid Remodeling Triggered by Nitrogen and Phosphorus Starvation in Phaeodactylum

554 tricornutum, Plant Physiology, 167 (2015) 118-136. 
555 [5] Q. Hu, M. Sommerfeld, E. Jarvis, M. Ghirardi, M. Posewitz, M. Seibert, A. Darzins,

556 Microalgal triacylglycerols as feedstocks for biofuel production: perspectives and advances, The

557 Plant Journal, 54 (2008) 621-639.

558 [6] M. Hildebrand, A.K. Davis, S.R. Smith, J.C. Traller, R. Abbriano, The place of diatoms in

559 the biofuels industry, Biofuels, 3 (2012) 221-240.

560 [7] C. Ford, E. Percival, The carbohydrates of Phaeodactylum tricornutum. Part I. Preliminary

561 examination of the organism, and characterisation of low molecular weight material and of a

562 glucan, Journal of the Chemical Society (Resumed), (1965) 7035-7041.

563 [8] A. Bacic, G.B. Fincher, B.A. Stone, Chemistry, biochemistry, and biology of 1-3 beta

564 glucans and related polysaccharides, Academic Press, 2009.

565 [9] E. Granum, S.M. Myklestad, A simple combined method for determination of $\beta$-1,3-glucan

566 and cell wall polysaccharides in diatoms, Hydrobiologia, 477 (2002) 155-161.

567 [10] A. Chiovitti, P. Molino, S.A. Crawford, R. Teng, T. Spurck, R. Wetherbee, The glucans

568 extracted with warm water from diatoms are mainly derived from intracellular chrysolaminaran

569 and not extracellular polysaccharides, European Journal of Phycology, 39 (2004) 117-128.

570 [11] B. Gügi, T. Le Costaouec, C. Burel, P. Lerouge, W. Helbert, M. Bardor, Diatom-Specific

571 Oligosaccharide and Polysaccharide Structures Help to Unravel Biosynthetic Capabilities in

572 Diatoms, Marine Drugs, 13 (2015) 5993-6018.

573 [12] C. Ford, E. Percival, The carbohydrates of Phaeodactylum tricornutum. Part II. A sulphated

574 glucuronomannan, Journal of the Chemical Society (Resumed), (1965) 7042-7046.

575 [13] L. Waterkeyn, A. Bienfait, Localisation et rôle des $\beta$-1, 3-glucanes (callose et

576 chrysolaminarine) dans le genre Pinnularia (diatomées), La Cellule, 74 (1987) 198-226. 
577 [14] J. Blackwell, K.D. Parker, K.M. Rudall, Chitin fibres of the diatoms Thalassiosira fluviatilis 578 and Cyclotella cryptica, Journal of Molecular Biology, 28 (1967) 383-385.

579 [15] S.N. Aslam, T. Cresswell-Maynard, D.N. Thomas, G.J.C. Underwood, Production and

580 Characterization of the Intra- and Extracellular Carbohydrates and Polymeric Substances (EPS)

581 of Three Sea-Ice Diatom Species, and Evidence for a Cryoprotective Role for EPS, Journal of

582 Phycology, 48 (2012) 1494-1509.

583 [16] T.A. Scott, E.H. Melvin, Determination of Dextran with Anthrone, Analytical Chemistry, 25

$584 \quad$ (1953) 1656-1661.

585 [17] M. DuBois, K.A. Gilles, J.K. Hamilton, P.A. Rebers, F. Smith, Colorimetric Method for

586 Determination of Sugars and Related Substances, Analytical Chemistry, 28 (1956) 350-356.

587 [18] M.S. Chauton, P. Winge, T. Brembu, O. Vadstein, A.M. Bones, Gene Regulation of Carbon

588 Fixation, Storage, and Utilization in the Diatom Phaeodactylum tricornutum Acclimated to

589 Light/Dark Cycles, Plant Physiology, 161 (2013) 1034-1048.

590 [19] L.T. Guerra, O. Levitan, M.J. Frada, J.S. Sun, P.G. Falkowski, G.C. Dismukes, Regulatory

591 branch points affecting protein and lipid biosynthesis in the diatom Phaeodactylum tricornutum,

592 Biomass \& Bioenergy, 59 (2013) 306-315.

593 [20] A.S. Mirón, M.C.C. García, A.C. Gómez, F.G.a. Camacho, E.M. Grima, Y. Chisti, Shear

594 stress tolerance and biochemical characterization of Phaeodactylum tricornutum in quasi steady-

595 state continuous culture in outdoor photobioreactors, Biochemical Engineering Journal, 16

596 (2003) 287-297.

597 [21] G.E. Anthon, D.M. Barrett, Determination of Reducing Sugars with 3-Methyl-2-

598 benzothiazolinonehydrazone, Analytical Biochemistry, 305 (2002) 287-289. 
599 [22] R. Radakovits, R.E. Jinkerson, A. Darzins, M.C. Posewitz, Genetic Engineering of Algae 600 for Enhanced Biofuel Production, Eukaryotic Cell, 9 (2010) 486-501.

601 [23] K.M. Vårum, S. Myklestad, Effects of light, salinity and nutrient limitation on the 602 production of $\beta$-1,3-d-glucan and exo-d-glucanase activity in Skeletonema costatum (Grev.)

603 Cleve, Journal of Experimental Marine Biology and Ecology, 83 (1984) 13-25.

604 [24] N.L. Hockin, T. Mock, F. Mulholland, S. Kopriva, G. Malin, The Response of Diatom 605 Central Carbon Metabolism to Nitrogen Starvation Is Different from That of Green Algae and 606 Higher Plants, Plant Physiology, 158 (2012) 299-312.

607 [25] T. Lacour, A. Sciandra, A. Talec, P. Mayzaud, O. Bernard, Diel Variations of 608 Carbohydrates and Neutral Lipids in Nitrogen-Sufficient and Nitrogen-Starved Cyclostat 609 Cultures of Isochrysis Sp., Journal of Phycology, 48 (2012) 966-975.

610 [26] L. Alipanah, J. Rohloff, P. Winge, A.M. Bones, T. Brembu, Whole-cell response to nitrogen 611 deprivation in the diatom Phaeodactylum tricornutum, Journal of Experimental Botany, 66 612 (2015) 6281-6296.

613 [27] G. Breuer, P.P. Lamers, D.E. Martens, R.B. Draaisma, R.H. Wijffels, The impact of 614 nitrogen starvation on the dynamics of triacylglycerol accumulation in nine microalgae strains, 615 Bioresource Technology, 124 (2012) 217-226.

616 [28] M.T. Juergens, R.R. Deshpande, B.F. Lucker, J.-J. Park, H. Wang, M. Gargouri, F.O.

617 Holguin, B. Disbrow, T. Schaub, J.N. Skepper, D.M. Kramer, D.R. Gang, L.M. Hicks, Y.

618 Shachar-Hill, The Regulation of Photosynthetic Structure and Function during Nitrogen

619 Deprivation in Chlamydomonas reinhardtii, Plant Physiology, 167 (2015) 558-573. 
620 [29] R. Tevatia, J. Allen, P. Blum, Y. Demirel, P. Black, Modeling of rhythmic behavior in

621 neutral lipid production due to continuous supply of limited nitrogen: Mutual growth and lipid

622 accumulation in microalgae, Bioresource Technology, 170 (2014) 152-159.

623 [30] M. Chen, H. Tang, H. Ma, T.C. Holland, K.Y.S. Ng, S.O. Salley, Effect of nutrients on 624 growth and lipid accumulation in the green algae Dunaliella tertiolecta, Bioresource Technology, $625102(2011) 1649-1655$.

626 [31] Z.T. Wang, N. Ullrich, S. Joo, S. Waffenschmidt, U. Goodenough, Algal Lipid Bodies:

627 Stress Induction, Purification, and Biochemical Characterization in Wild-Type and Starchless

628 Chlamydomonas reinhardtii, Eukaryotic Cell, 8 (2009) 1856-1868.

629 [32] V.H. Work, R. Radakovits, R.E. Jinkerson, J.E. Meuser, L.G. Elliott, D.J. Vinyard, L.M.L.

630 Laurens, G.C. Dismukes, M.C. Posewitz, Increased Lipid Accumulation in the Chlamydomonas

631 reinhardtii sta7-10 Starchless Isoamylase Mutant and Increased Carbohydrate Synthesis in

632 Complemented Strains, Eukaryotic Cell, 9 (2010) 1251-1261.

633 [33] B.-H. Zhu, H.-P. Shi, G.-P. Yang, N.-N. Lv, M. Yang, K.-H. Pan, Silencing UDP-glucose

634 pyrophosphorylase gene in Phaeodactylum tricornutum affects carbon allocation, New

635 Biotechnology, 33 (2015) 237-244.

636 [34] F. Daboussi, S. Leduc, A. Maréchal, G. Dubois, V. Guyot, C. Perez-Michaut, A. Amato, A.

637 Falciatore, A. Juillerat, M. Beurdeley, D.F. Voytas, L. Cavarec, P. Duchateau, Genome

638 engineering empowers the diatom Phaeodactylum tricornutum for biotechnology, Nature

639 Communications, 5 (2014).

640 [35] Y. Zhang, Y. Liu, X. Cao, P. Gao, X. Liu, X. Wang, J. Zhang, J. Zhou, S. Xue, G. Xu, J.

641 Tian, Free amino acids and small molecular acids profiling of marine microalga Isochrysis

642 zhangjiangensis under nitrogen deficiency, Algal Research, 13 (2016) 207-217. 
643 [36] T.R. Hauser, R.L. Cummins, Increasing Sensitivity of 3-Methyl-2-Benzothiazolone

644 Hydrozone Test for Analysis of Aliphatic Aldehydes in Air, Analytical Chemistry, 36 (1964)

$645 \quad 679-681$.

646 [37] J. Dean Pakulski, R. Benner, An improved method for the hydrolysis and MBTH analysis of 647 dissolved and particulate carbohydrates in seawater, Marine Chemistry, 40 (1992) 143-160.

648 [38] G.E. Anthon, D.M. Barrett, Kinetic Parameters for the Thermal Inactivation of Quality649 Related Enzymes in Carrots and Potatoes, Journal of Agricultural and Food Chemistry, 50 $650 \quad$ (2002) 4119-4125.

651 [39] S. Jarle Horn, V.G.H. Eijsink, A reliable reducing end assay for chito-oligosaccharides, 652 Carbohydrate Polymers, 56 (2004) 35-39.

653 [40] S. Van Wychen, L.M. Laurens, Determination of total carbohydrates in algal biomass, 654 NREL, TP-5100-60957, 〈http://www.nrel.gov/docs/fy16osti/60957.pdf〉.

655 [41] R.R.L. Guillard, Culture of Phytoplankton for Feeding Marine Invertebrates, in: W.L.

656 Smith, M.H. Chanley (Eds.) Culture of Marine Invertebrate Animals: Proceedings - 1st

657 Conference on Culture of Marine Invertebrate Animals Greenport, Springer US, Boston, MA, 658 1975, pp. 29-60.

659 [42] S. Bhamidi, L. Shi, D. Chatterjee, J.T. Belisle, D.C. Crick, M.R. McNeil, A bioanalytical 660 method to determine the cell wall composition of Mycobacterium tuberculosis grown in vivo, 661 Analytical Biochemistry, 421 (2012) 240-249.

662 [43] Y.-T. Kim, E.-H. Kim, C. Cheong, D.L. Williams, C.-W. Kim, S.-T. Lim, Structural 663 characterization of $\beta$-D-(1 $\rightarrow 3,1 \rightarrow 6)$-linked glucans using NMR spectroscopy, Carbohydrate 664 Research, 328 (2000) 331-341. 
665 [44] R.J. Ritchie, Universal chlorophyll equations for estimating chlorophylls a, b, c, and d and 666 total chlorophylls in natural assemblages of photosynthetic organisms using acetone, methanol, 667 or ethanol solvents, Photosynthetica, 46 (2008) 115-126.

668 [45] T. Govender, L. Ramanna, I. Rawat, F. Bux, BODIPY staining, an alternative to the Nile 669 Red fluorescence method for the evaluation of intracellular lipids in microalgae, Bioresource 670 Technology, 114 (2012) 507-511.

671 [46] D. Jallet, M.A. Caballero, A.A. Gallina, M. Youngblood, G. Peers, Photosynthetic 672 physiology and biomass partitioning in the model diatom Phaeodactylum tricornutum grown in a 673 sinusoidal light regime, Algal Research, 18 (2016) 51-60.

674 [47] M.A. Danielewicz, L.A. Anderson, A.K. Franz, Triacylglycerol profiling of marine 675 microalgae by mass spectrometry, Journal of Lipid Research, 52 (2011) 2101-2108.

676 [48] I. Grouneva, T. Jakob, C. Wilhelm, R. Goss, The regulation of xanthophyll cycle activity 677 and of non-photochemical fluorescence quenching by two alternative electron flows in the 678 diatoms Phaeodactylum tricornutum and Cyclotella meneghiniana, Biochimica et Biophysica 679 Acta (BBA) - Bioenergetics, 1787 (2009) 929-938.

680 [49] R.J. Olson, E.R. Zettler, O.K. Anderson, Discrimination of eukaryotic phytoplankton cell 681 types from light scatter and autofluorescence properties measured by flow cytometry, Cytometry, $68210(1989) 636-643$.

683 [50] N.R. Baker, Chlorophyll Fluorescence: A Probe of Photosynthesis In Vivo, Annual Review 684 of Plant Biology, 59 (2008) 89-113.

685 [51] A.S. Abdullahi, G.J.C. Underwood, M.R. Gretz, Extracellular Matrix Assembly In Diatoms 686 (Bacillariophyceae). V. Environmental Effects On Polysaccharide Synthesis In The Model 687 Diatom, Phaeodactylum tricornutum, Journal of Phycology, 42 (2006) 363-378. 
688 [52] T.R. Størseth, K. Hansen, K.I. Reitan, J. Skjermo, Structural characterization of $\beta$-d-( $1 \rightarrow 3)$ 689 glucans from different growth phases of the marine diatoms Chaetoceros mülleri and 690 Thalassiosira weissflogii, Carbohydrate Research, 340 (2005) 1159-1164.

691 [53] T.R. Størseth, S. Kirkvold, J. Skjermo, K.I. Reitan, A branched $\beta$-d-(1 $\rightarrow 3,1 \rightarrow 6)$-glucan 692 from the marine diatom Chaetoceros debilis (Bacillariophyceae) characterized by NMR, 693 Carbohydrate Research, 341 (2006) 2108-2114.

694 [54] S. Xia, B. Gao, A. Li, J. Xiong, Z. Ao, C. Zhang, Preliminary characterization, antioxidant 695 properties and production of chrysolaminarin from marine diatom Odontella aurita, Marine 696 Drugs, 12 (2014) 4883-4897.

697 [55] L.M.L. Laurens, T.A. Dempster, H.D.T. Jones, E.J. Wolfrum, S. Van Wychen, J.S.P.

698 McAllister, M. Rencenberger, K.J. Parchert, L.M. Gloe, Algal Biomass Constituent Analysis: 699 Method Uncertainties and Investigation of the Underlying Measuring Chemistries, Analytical 700 Chemistry, 84 (2012) 1879-1887.

701 [56] K.M. Varum, K. Ostgaard, K. Grimsrud, Diurnal Rhythms in Carbohydrate-Metabolism of 702 the Marine Diatom Skeletonema-Costatum (Grev) Cleve, Journal of Experimental Marine 703 Biology and Ecology, 102 (1986) 249-256.

704 [57] R.J. Geider, J. La Roche, R.M. Greene, M. Olaizola, Response Of The Photosynthetic 705 Apparatus Of Phaeodactylum tricornutum (Bacillariophyceae) To Nitrate, Phosphate, Or Iron 706 Starvation, Journal of Phycology, 29 (1993) 755-766.

707 [58] M. Palmucci, S. Ratti, M. Giordano, Ecological and Evolutionary Implications of Carbon 708 Allocation in Marine Phytoplankton as a Function of Nitrogen Availability: A Fourier Transform 709 Infrared Spectroscopy Approach, Journal of Phycology, 47 (2011) 313-323. 
710 [59] F. Mus, J.-P. Toussaint, K.E. Cooksey, M.W. Fields, R. Gerlach, B.M. Peyton, R.P.

711 Carlson, Physiological and molecular analysis of carbon source supplementation and $\mathrm{pH}$ stress-

712 induced lipid accumulation in the marine diatom Phaeodactylum tricornutum, Applied

713 Microbiology and Biotechnology, 97 (2013) 3625-3642.

714 [60] S. Myklestad, Production of carbohydrates by marine planktonic diatoms. I. Comparison of

715 nine different species in culture, Journal of Experimental Marine Biology and Ecology, 15

716 (1974) 261-274.

717 [61] E. Granum, K. Ståle, S.M. Myklestad, Cellular and extracellular production of

718 carbohydrates and amino acids by the marine diatom Skeletonema costatum: diel variations and

719 effects of N depletion, Marine Ecology Progress Series, 242 (2002) 83-94. 
721 Table 1: Structural analysis of laminarin and soluble

722 polysaccharide extracted from $P$. tricornutum using

723 annotated $\beta-1,3$ glucan signatures.

\begin{tabular}{|c|c|c|c|}
\hline & $\begin{array}{c}\text { Kim et al. } \\
\text { (2000) }\end{array}$ & \multicolumn{2}{|c|}{ This study } \\
\hline substrate & laminarin & laminarin & soluble glucan (P.t.) \\
\hline $\mathrm{DP}^{\mathrm{a}}$ & 33 & 28 & 17 \\
\hline $\mathrm{DB}^{\mathrm{b}}$ & 0.07 & 0.063 & 0.015 \\
\hline $\mathrm{DP} \times \mathrm{DB}^{\mathrm{c}}$ & 2.3 & 1.7 & 0.26 \\
\hline
\end{tabular}

$724{ }^{\mathrm{a}} \mathrm{DP}$ - degree of polymerization, ${ }^{\mathrm{b}} \mathrm{DB}$ - degree of branching, ${ }^{c}$ number of branches per molecule 
725 Figures

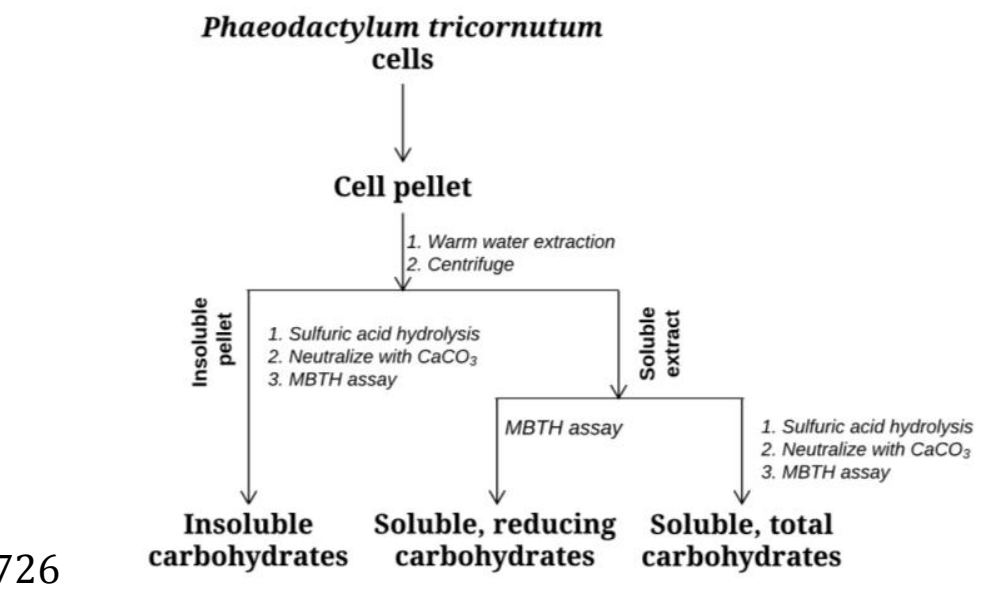

\section{Figure 1: Overview of carbohydrate pools resolved by an integrative MBTH method.}

728 Insoluble sugars; Soluble, reducing sugars; and Soluble, total sugars are resolved by a warm

729 water extraction, selective hydrolysis, and quantification with the MBTH reducing sugar assay.

730 Compositionally, these three fractions represent structural carbohydrates, monosaccharides, and

731 monosaccharides plus polysaccharides, respectively. The polysaccharide fraction (soluble,

732 nonreducing carbohydrates) is determined by subtracting the soluble, reducing concentration

733 from the soluble, total concentration. 


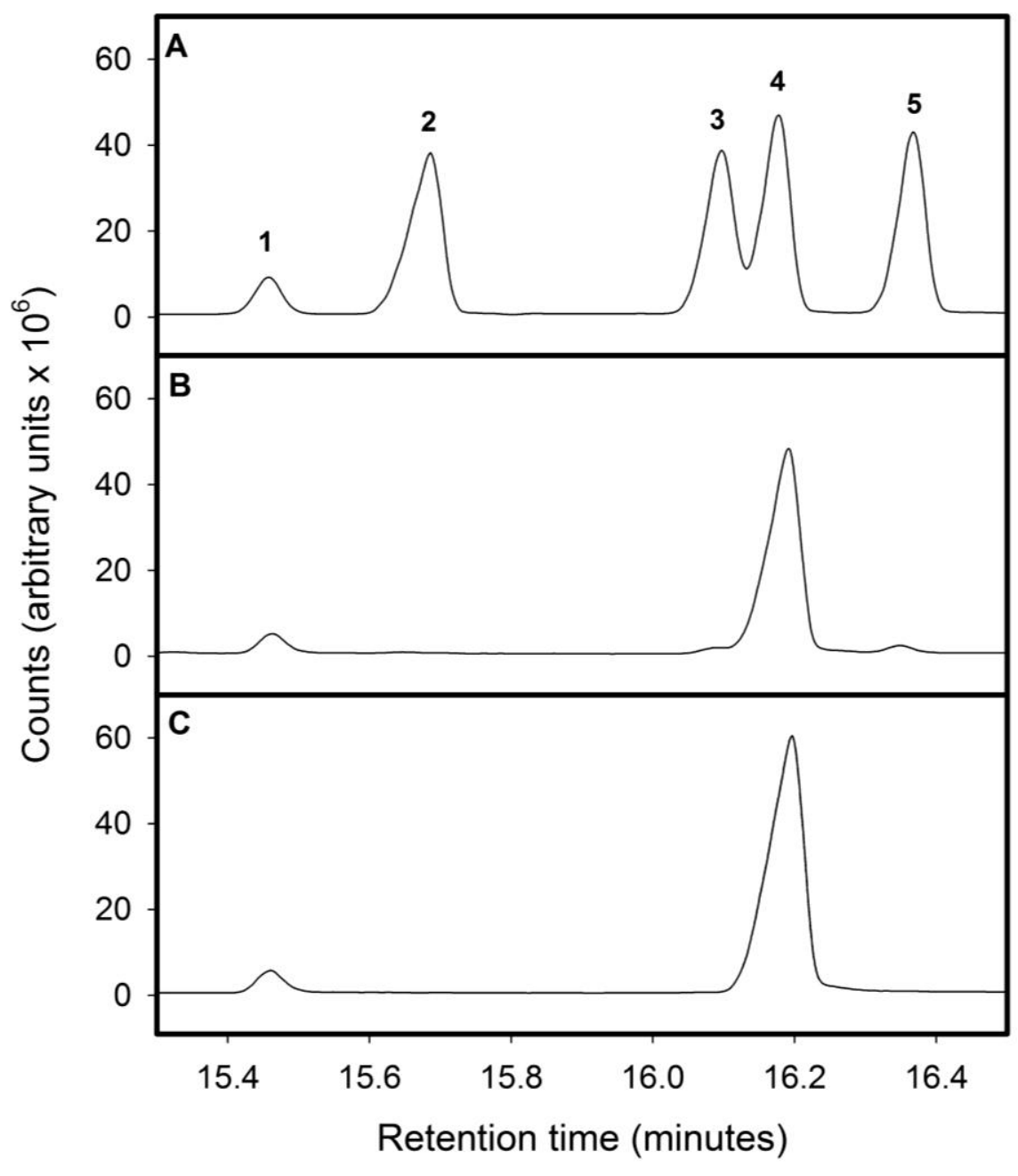

735 Figure 2: Hexose composition analyses of laminarin and soluble glucan extracted from

736 Phaeodactylum tricornutum. Gas chromatography traces of the neutral sugar standard (A),

737 laminarin (B), and soluble glucan extracted from Phaeodactylum tricornutum (C). The neutral

738 sugar standard contains the internal standard 3-O-methylglucose (1), myo-inositol (2), mannose

739 (3), glucose (4), and galactose (5). 


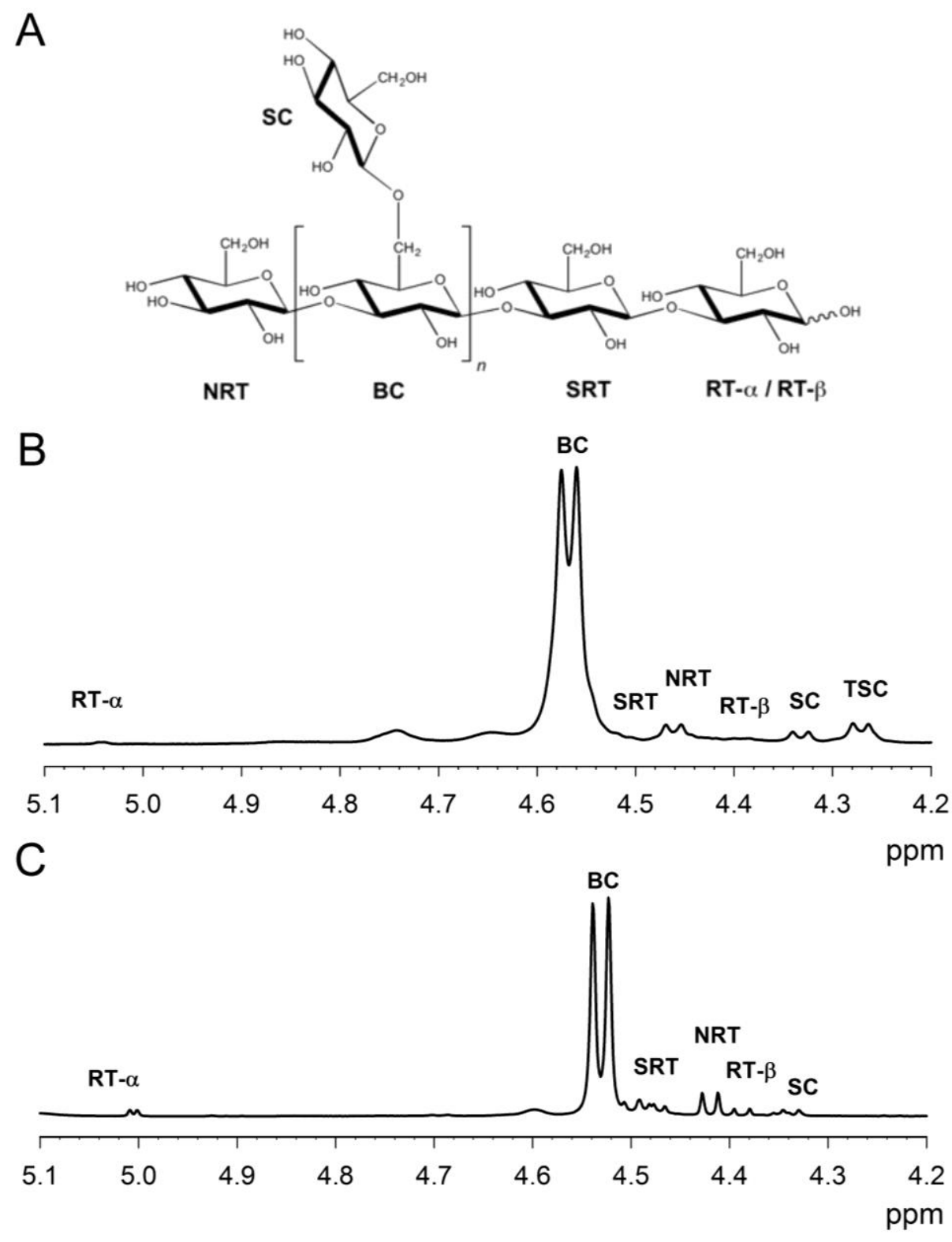

741 Figure 3: ${ }^{1}$ H-NMR structural analysis of soluble polysaccharide extracted from

742 Phaeodactylum tricornutum. A reference model of a $\beta$-glucan with labeled anhydrous glucose

743 units (AGU) whose unique ${ }^{1} \mathrm{H}$ correspond to previously annotated chemical shifts (A). The ${ }^{1} \mathrm{H}-$

744 NMR spectra of laminarin (B) and the purified, soluble polysaccharide from Phaeodactylum

745 tricornutum (C) in DMSO- $\mathrm{d}_{6}$ at $80{ }^{\circ} \mathrm{C}$ are also presented. The major glucose doublet is the

746 backbone chain (BC) and minor peaks include reducing terminal (RT, either $\alpha$ or $\beta$ anomer), 
747 second AGU adjacent to the reducing terminal (SRT), nonreducing terminal (NRT), side chain

748 (SC), and the terminal AGU of the SC (TSC). 


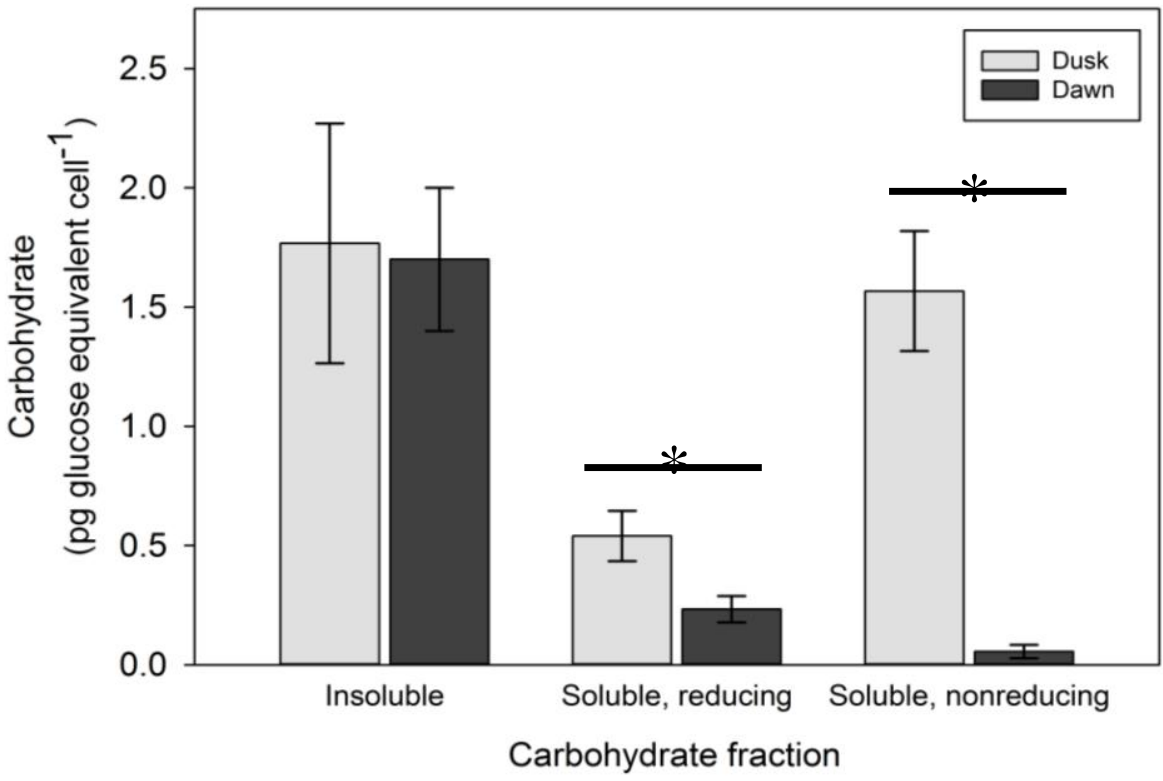

$750 \quad$ Figure 4: Average carbohydrate fraction quantities extracted from Phaeodactylum

751 tricornutum at dawn and dusk. $(\mathrm{n}=3$, error $=$ standard deviation; Paired student's T-test, $*=\mathrm{p}$ $752<0.05)$. 
A

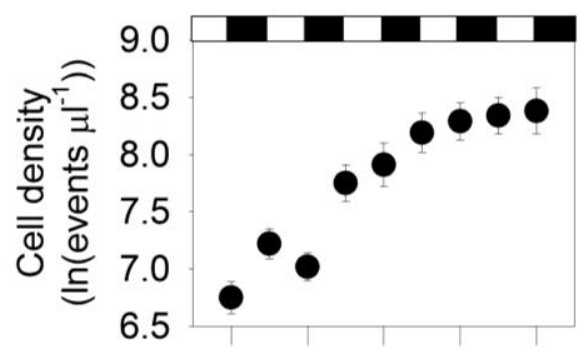

C

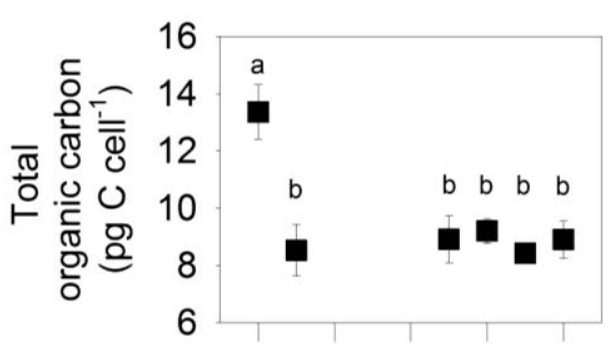

E

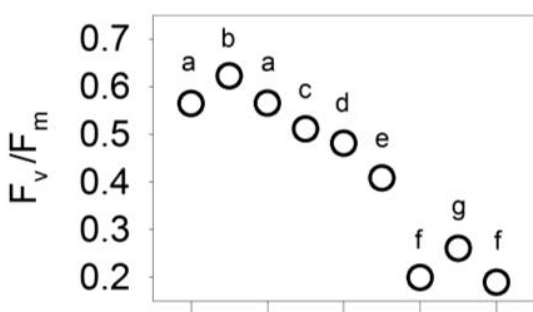

G

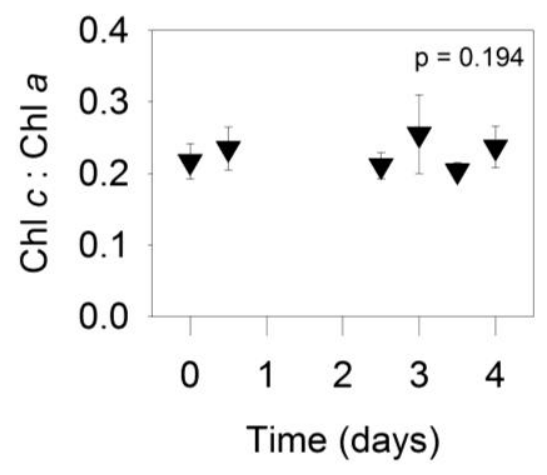

B

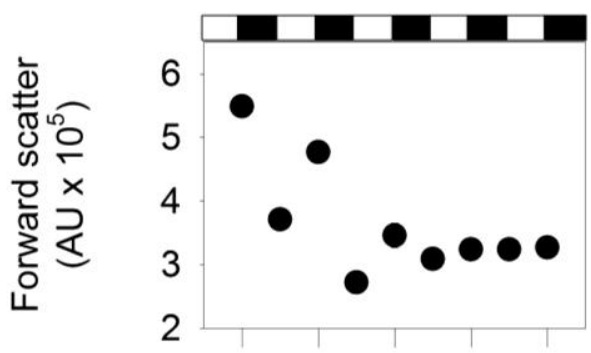

D

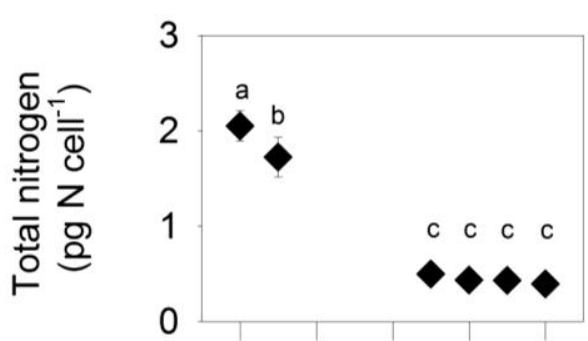

$\mathbf{F}$

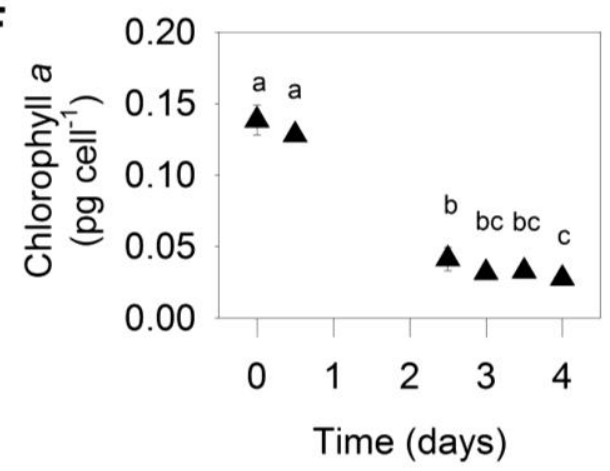

Figure 5: Cell physiology changes during nitrate deprivation. Cell density (A), cell size

755 approximated by mean forward scatter per cell (B), total organic carbon (C), total nitrogen (D),

$756 \quad \mathrm{~F}_{\mathrm{v}} / \mathrm{F}_{\mathrm{m}}(\mathrm{E})$, chlorophyll $a(\mathrm{~F})$, and the chlorophyll $c$ : chlorophyll $a$ ratio $(\mathrm{G})$ are depicted above.

757 Black and white bars at the top of the figure represents day and night, respectively. Different

758 letters represent statistically different groups from a Tukey's HSD post-hoc test after a repeated 
759 measures one way ANOVA $(n=5$, error = standard deviation, error bars may be smaller than

760 symbol). 
A

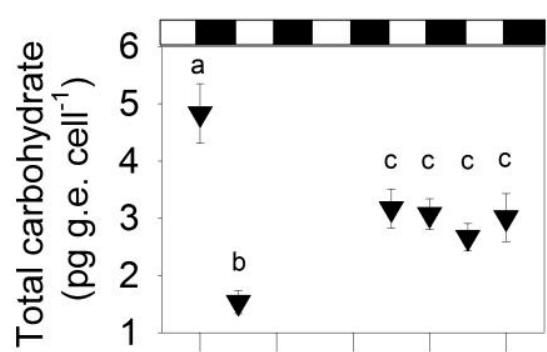

C

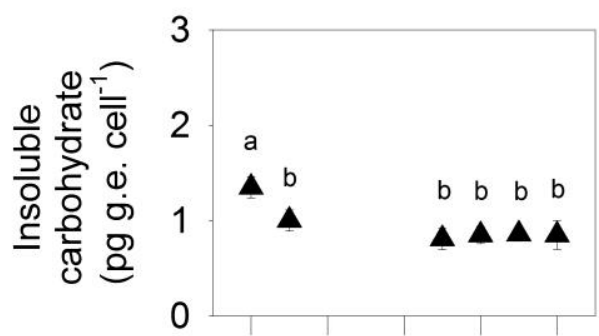

E

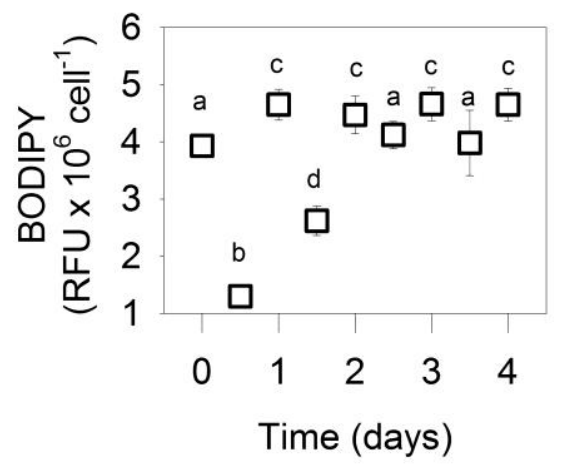

B

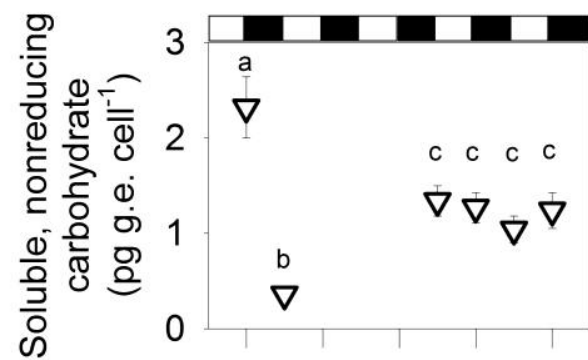

D

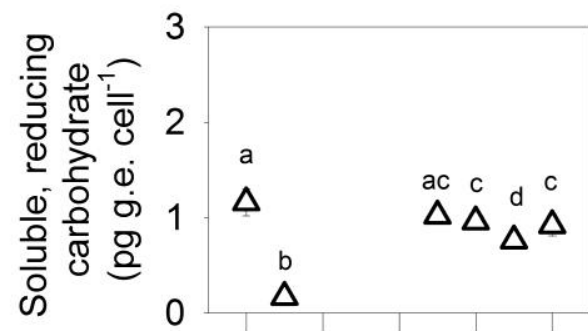

$\mathbf{F}$

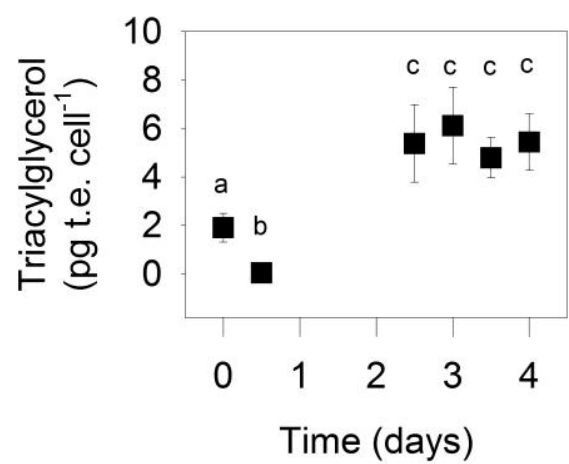

762 Figure 6: Quantifying carbohydrate fractions and neutral lipid during nitrate deprivation.

763 The sum of all quantified carbohydrate fractions (A) is shown alongside soluble, nonreducing

764 (B), insoluble (C), and soluble, reducing (D), carbohydrates and are reported as glucose

765 equivalents (g.e.). Mean BODIPY fluorescence (E) and triacylglycerol (F) in tripalmitin

766 equivalents (t.e.) are also reported. Black and white bars at the top of the figure represent day and

767 night, respectively. Different letters represent statistically different groups from a Tukey’s HSD

768 post-hoc test after a repeated measures one way ANOVA $(n=3-5$, error $=$ standard deviation,

769 error bars may be smaller than symbol). 


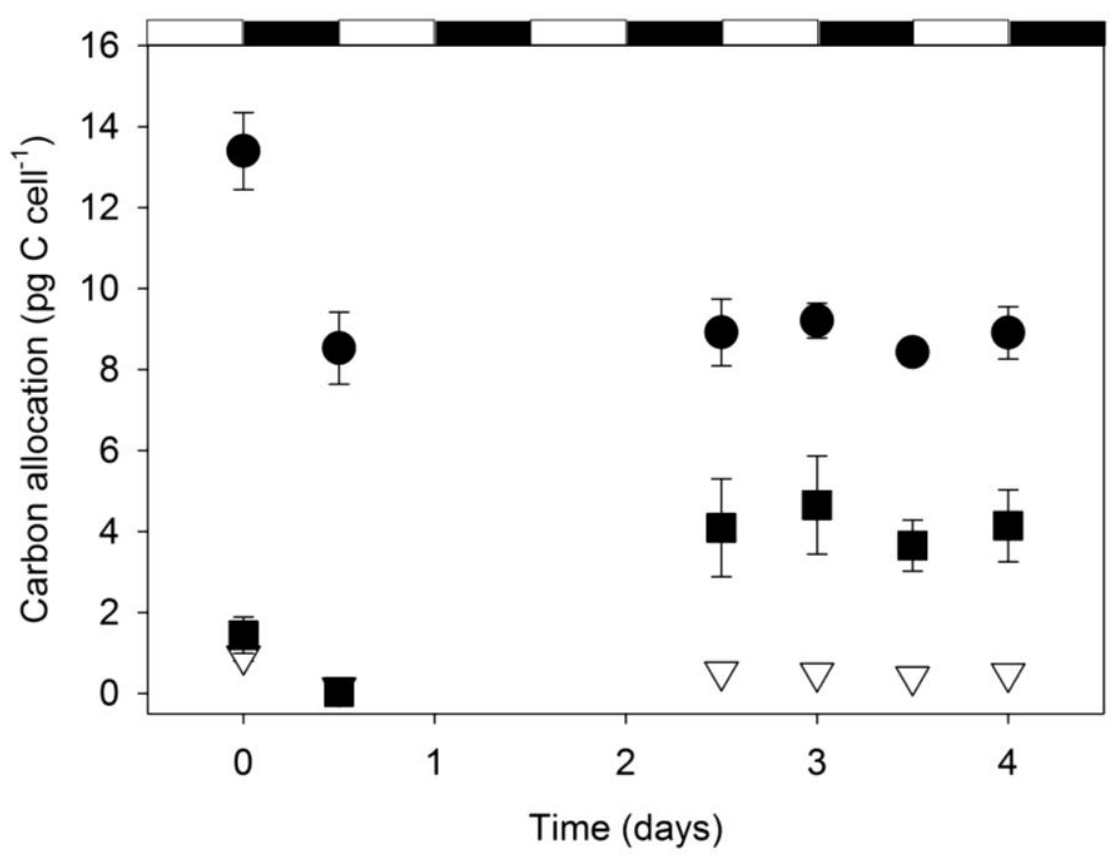

771 Figure 7: Carbon partitioning into storage metabolites during nitrate deprivation. Black

772 and white bars at the top of the figure represent day and night, respectively. Total carbon per cell

773 is included as a reference (circles) for the total amount of carbon contributed by the storage

774 metabolites triacyglycerol (squares) and soluble, nonreducing carbohydrate (inverted triangles).

775 Mean triacylglycerol and soluble, nonreducing carbohydrate per cell were multiplied by carbon

776 mass fractions for tripalmitin $\left(\mathrm{C}_{51} \mathrm{H}_{98} \mathrm{O}_{6} ; 0.76\right)$ and glucose $\left(\mathrm{C}_{6} \mathrm{H}_{12} \mathrm{O}_{6} ; 0.4\right)(\mathrm{n}=3-5$, error $=$

777 standard deviation, error bars may be smaller than symbol). 